\title{
Prognostic value of thumb pain sensation in birth brachial plexopathy
}

\author{
Valor prognóstico da sensibilidade dolorosa do polegar na \\ plexopatia braquial relacionada ao parto \\ Carlos O. Heise, Roberto S. Martins, Luciano H. Foroni, Mário G. Siqueira
}

\begin{abstract}
Objective: To evaluate the prognostic value of absent thumb pain sensation in newborns and young infants with birth brachial plexopathy. Methods: We evaluated 131 patients with birth brachial plexopathy with less than two months of age. Pain sensation was evoked by thumb nail bed compression to evaluate sensory fibers of the upper trunk (C6). The patients were followed-up monthly. Patients with less than antigravity elbow flexion at six months of age were considered to have a poor outcome. Results: Thirty patients had absent thumb pain sensation, from which 26 showed a poor outcome. Sensitivity of the test was $65 \%$ and specificity was $96 \%$. Conclusion: Evaluation of thumb pain sensation should be included in the clinical assessment of infants with birth brachial plexopathy.
\end{abstract}

Key words: brachial plexus, pain perception, prognosis.

RESUMO

Objetivo: Avaliar o valor prognóstico da hipoestesia dolorosa no polegar em recém-nascidos e lactentes jovens com plexopatia braquial obstétrica. Métodos: Avaliamos 131 pacientes com plexopatia braquial obstétrica com menos de dois meses de idade. A sensação dolorosa foi provocada pela compressão do leito ungueal do polegar para avaliar fibras sensitivas do tronco superior (C6). Os pacientes foram seguidos mensalmente. Prognóstico desfavorável foi atribuído aos pacientes sem força antigravitacional para flexão do cotovelo aos seis meses de idade. Resultados: Trinta pacientes apresentaram hipoestesia dolorosa do polegar, dos quais 26 tiveram prognóstico desfavorável. A sensibilidade do teste foi de $65 \%$ e a especificidade $96 \%$. Conclusão: A avaliação da sensibilidade dolorosa do polegar deve ser incluída na avaliação clínica de pacientes com plexopatia braquial obstétrica.

Palavras-Chave: plexo braquial, percepção da dor, prognóstico.

Birth brachial plexopathy incidence is 1.5:1000 live-births ${ }^{1,2}$ and it has not declined in the last years ${ }^{3}$. Fortunately, most of these children recover well, but not all ${ }^{4-6}$. Surgical reconstruction of the brachial plexus can be offered for children with severe lesions, but the selection criteria and timing of the procedure are still matters of controversy ${ }^{7}$. Early interventions carry a better prognosis $^{8-10}$, but this could mean unnecessary surgery in some patients ${ }^{11}$. Surgeons rely their decision weather to operate or not based on specific motor clinical parameters at certain age, varying between up to three and nine months ${ }^{8-14}$. The most popular criterion was created by Gilbert et al. ${ }^{8}$ and it is based on absent biceps function at three months of age. Others use a more conservative approach, such as O'Brien at al. ${ }^{14}$. Our clinical criterion has been absent antigravity elbow flexion at six months of age.

The initial clinical presentation has a clear relation with the final outcome. Patients with global paralysis usually have a poor prognosis ${ }^{7,9}$, but the outcome of patients with C5-C6 or C5-C6-C7 involvement is less clear ${ }^{5}$. In this group of patients, paralysis can be related to neurapraxia, in which motor fibers are blocked, but do not degenerate ${ }^{15}$. This picture can last for some months, and the outcome still should be good.

Evaluation of sensibility in newborns and young infants has not been emphasized because of lack of cooperation of the patients. However, it has already been noted that patients with sensory deficits carry a grim progno$\operatorname{sis}^{16}$. Thumb sensation is related to sensory fibers from the median nerve ascending through the upper trunk and mainly C6 root $^{17}$. Motor impairment of the upper trunk is always present in these patients, including biceps muscle. The objective of this study is to establish if thumb pain sensation can be used as a prognostic parameter in patients with birth brachial plexopathy. 
Table 1. Relation of thumb pain sensation during the first two months of age and Medical Research Council score of elbow flexion at six months of age. Patients with elbow flexion score below grade 3 were considered to have a poor outcome.

\begin{tabular}{lcc}
$\begin{array}{l}\text { Elbow flexion } \\
\text { (MRC score) }\end{array}$ & \multicolumn{2}{c}{$\begin{array}{c}\text { Thumb pain sensation } \\
\text { (number of patients) }\end{array}$} \\
\cline { 2 - 3 } & Absent & Present \\
\hline 0 & 8 & 3 \\
1 & 10 & 4 \\
2 & 8 & 7 \\
3 & 4 & 24 \\
4 & 0 & 22 \\
5 & 0 & 41 \\
\hline
\end{tabular}

MRC: Medical Research Council.

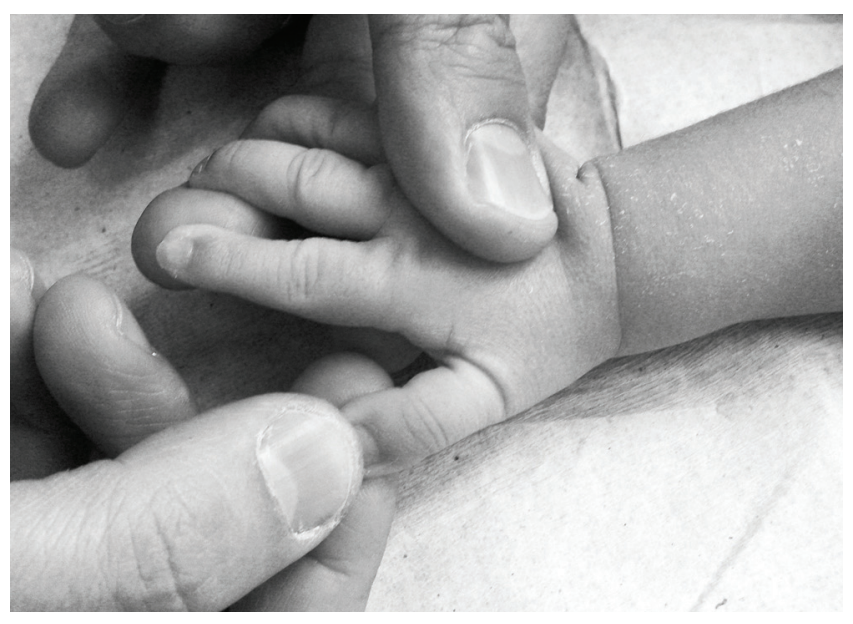

Figure. Thumb pain sensation testing in a newborn, evoked by digital compression of the nail bed.

\section{METHODS}

From December 2000 to February 2011, 160 patients with birth related brachial plexus lesions and less than 60 days of age were referred to the Peripheral Nerve Surgery Unit of the Neurosurgery Department of University of São Paulo Medical School. The diagnosis was clinically confirmed by a pediatric neurologist. Twenty-five patients were lost to follow-up, two were excluded because of bilateral lesions and two because of associated cerebral lesion. The remaining 131 patients were included in this study. The study was approved by the local ethical board.

There were 64 males and 67 females, ranging from 5 to 60 days of age. Birth weight ranged from $2000 \mathrm{~g}$ to $5520 \mathrm{~g}$ (median $3830 \mathrm{~g}$ ). There were 84 normal deliveries, including 4 breech presentations; 45 forceps assisted deliveries and 2 cesarean sections. The right side was affected in 88 patients and the left side in 43. We classified the level of involvement of the patients according to the innervation pattern of the weak muscles. There were 77 lesions involving C5-C6 levels, 37 involving C5C6-C7 levels, and 17 patients with global paralysis.
All the patients were followed-up on a monthly basis by the same child neurologist, using a standard evaluation protocol. Pain sensation was evoked by digital compression of thumb nail bed (Figure). The amount of force was not standardized, but it was not more than $2 \mathrm{kgf}$. No patient developed nail bed hematomas after the test. Crying or facial grimace were considered normal responses. The healthy side was tested as a control. If the child showed no response to thumb nail compression on the affected side and normal response on the control side, the test was considered abnormal. If the child was already crying before the sensory test, we repeated the test after breastfeeding. If we still could not perform the test, another appointment was rescheduled. Absence of thumb pain sensation was confirmed in at least two evaluations performed on separated days. We analyzed pain testing only up to three months of age.

The evaluation protocol included power assessment of several muscle groups using a modified Medical Research Council (MRC) motor scale, including elbow flexion. The difference between grades 3,4 , and 5 was based on range of motion (3: less than 50\%, 4: more than 50\%, 5: no asymmetry). We evaluated elbow flexion at six months of age and correlated that with thumb pain sensation during the first two months of age. Patients with less than antigravity elbow flexion at six months of age were considered to have a poor outcome.

Statistic analysis was performed using Chi-square test. We calculated sensitivity and specificity of absent thumb pain sensation for predicting a poor outcome. We also calculated the relative risk of a patient with absent finger pain sensation for a poor outcome, including the $95 \%$ confidence interval.

\section{RESULTS}

Sensory testing could be done in all 131 patients. Thumb pain sensation was normal in 101 patients $(77 \%)$ and absent in $30(23 \%)$. Patients with absent thumb pain sensation included 15 patients with global paralysis, 14 patients with C5C7 involvement and only one patient with motor involvement restricted to C5-C6 levels.

Forty patients were considered to have a poor outcome based on elbow flexion score at six months of age, including 15 patients with global paralysis, 19 patients with C5C7 involvement and six patients with C5-C6 involvement. For purpose of this study, hand function was not considered. All 17 patients with global paralysis had poor hand function at six months.

Absent thumb pain sensation was highly associated with a poor outcome $(p<0.001)$, with a sensitivity of $65 \%$ and specificity of $96 \%$. The positive predictive value was $87 \%$, and the negative predictive value was $86 \%$. The relative risk for a poor outcome in an infant with absent thumb pain sensation was 
6.3 times higher (95\% confidence interval: 3.8-10.4). The distribution of elbow flexion MRC scores in the patients with and without thumb pain sensation is seen in Table.

\section{DISCUSSION}

Our results show that the evaluation of thumb pain sensation is a valuable prognostic tool in newborns and young infants. Absent thumb pain sensation indicated a poor outcome with good specificity. Lack of specificity is a major concern of Gilbert's criterion for surgery indication: absent biceps function with three months of age ${ }^{7,18}$. Unfortunately, sensitivity of the test was poor. It was rare for a patient with motor involvement restricted to C5-C6 levels to show absent thumb pain sensation. On the other hand, this was usually seen in patients with complete paralysis. Perhaps the most useful information was obtained in patients with C5-C7 involvement, which showed absent thumb pain sensation in $37 \%$ of the cases.

Sensory testing in infants is challenging. However, we think that testing babies with less than two months of age is much easier than testing older children. Young infants showed a very stereotyped pain response to thumb nail bed compression, which lasted only for a few seconds. They are not afraid of the physician, as is the case of older children. The sensory test did also not impress the parents, and none of them asked to stop the testing. The ability to perform the sensory testing is related to feeding timing. If the infant is hungry, it is often impossible to do it. The ideal moment to perform the test is about one hour after feeding, because the child is neither agitated nor drowsy.

Why are motor impairments much more evident than pain sensory deficits in birth related brachial plexus injuries? One possible explanation is that the dermatomes overlap extensively; so, many adjacent spinal levels should be compromised in order to generate a sensory deficit ${ }^{19}$. Collon et al. also suggested the possibility of alternative paths for peripheral sensory information in young infants with brachial plexus lesions ${ }^{20}$. One very tempting explanation is related to the physiopathology of neurapraxia ${ }^{21}$. Neurapraxia is related to conduction block of nerve fibers, which affect thick and myelinated fibers, as the motor fibers. However, pain sensation is mediated by thin nerve fibers (A $\delta$ and $\mathrm{C}$ fibers), which are resistant to conduction block. Therefore, it is expected that patients with neurapraxia should not have pain sensory deficits.

In conclusion, our sensory testing protocol is very easy to perform and can be done in just a few seconds. Despite the poor sensitivity, we think that it should be incorporated to the routine clinical examination of young infants with brachial plexus lesions. Other studies are needed to confirm our findings, including a blinded prospective long term study and the evaluation of the sensory test reproducibility.

\section{References}

1. Gilbert WM, Nesbitt TS, Danielsen B. Associated factors in 1611 cases of brachial plexus injury. Obstet Gynecol 1999;93:536-540.

2. Foad SL, Mehlman CT, Ying J. The epidemiology of neonatal brachial plexus palsy in the United States. J Bone Joint Surg Am 2008;90:1258-1264.

3. Mollberg M, Hagberg H, Bager B, Lilja H, Ladfors L. High birthweight and shoulder dystocia: the strongest risk factors for obstetrical brachial plexus palsy in a Swedish population-based study. Acta Obstet Gynecol Scand 2005;84:654-659.

4. Gordon M, Rich H, Deutschberger J, Green M. The immediate and longterm outcome of obstetric birth trauma: I. Brachial plexus paralysis. Am J Obstet Gynecol 1973;117:51-56.

5. Noetzel MJ, Park TS, Robinson S, Kaufman B. Prospective study of recovery following neonatal brachial plexus injury. J Child Neurol 2001;16:488-492.

6. Pondaag W, Malessy MJ, van Dijk JG, Thomeer RT. Natural history of obstetric brachial plexus palsy: a systematic review. Dev Med Child Neurol 2004;46:138-144.

7. Brauer CA, Waters PM. An economic analysis of the timing of microsurgical reconstruction in brachial plexus birth palsy. J Bone Joint Surg Am 2007;89: 970-978.

8. Gilbert A, Razaboni R, Amar-Khodja S. Indications and results of brachial plexus surgery in obstetrical palsy. Orthop Clin North Am 1988;19:91-105.

9. Hentz VR, Meyer RD. Brachial plexus microsurgery in children. Microsurgery 1991;12:175-185.

10. Terzis JK, Papakonstantinou KC. Management of obstetric brachial plexus palsy. Hand Clin 1999;15:717-736.
11. Spinner RJ, Kline DG. Surgery for peripheral nerve and brachial plexus injuries or other nerve lesions. Muscle Nerve 2000;23:680-695.

12. Clarke HM, Curtis CG. An approach to obstetrical brachial plexus injuries. Hand Clin 1995;4:563-581.

13. Grossman JA. Early operative intervention for birth injuries to the brachial plexus. Semin Pediatr Neurol 2000;7:36-43.

14. O'Brien DF, Park TS, Noetzel MJ, Weatherly T. Management of birth brachial plexus palsy. Childs Nerv Syst 2006;22:103-112.

15. Heise CO, Lorenzetti L, Marchese AJ, Gherpelli JL. Motor conduction studies for prognostic assessment of obstetrical plexopathy. Muscle Nerve 2004;30:451-455

16. Chung SM, Nissenbaum MM. Obstetrical paralysis. Orthop Clin North Am 1975;6:393-400.

17. Ferrante MA. Brachial plexopathies: classification, causes, and consequences. Muscle Nerve 2004;30:547-568.

18. Smith NC, Rowan P, Benson LJ, Ezaki M, Carter PR. Neonatal brachial plexus palsy. Outcome of absent biceps function at three months of age. J Bone Joint Surg A 2004;86:2163-2170.

19. Campbell WW. Sensory localization. In: Campbell WW (Ed). DeJong's The Neurologic Examination. 6th edition. Philadelphia; Lippincott Williams \& Wilkins: 2005.p. 455-465.

20. Colon AJ, Vredeveld JW, Blaauw G, Slooff AC, Richards R. Extensive somatosensory innervation in infants with obstetric brachial palsy. Clin Anat 2003;16:25-29.

21. Dumitru D, Zwarts MJ, Amato AA. Peripheral nervous system's reaction to injury. In:Dumitru D, Zwarts MJ, Amato AA (editors). Electrodiagnostic Medicine. 2nd edition. Philadelphia; Hanley \& Belfus; 2002. p. 115-158. 